\title{
Un cuarto de siglo con Cartas privadas de emigrantes a Indias. Prácticas y perspectivas de ediciones de cartas transatlánticas en el Imperio español/
}
A quarter of a century with Cartas privadas de emigrantes a Indias. Practices and perspectives of editions of transatlantic correspondences during the Spanish Empire

Werner Stangl

Universidad de Graz

Retomamos el 25. ${ }^{\circ}$ aniversario de de las Cartas privadas de Enrique Otte para hacer un repaso por las ediciones de similares cartas producidas desde entonces. Se analizan los fondos de los que se han sacado, se establece una tipología de cartas y se revisan las variadas prácticas de edición. También se proponen estándares de edición y se pronuncia por un cambio hacia ediciones digitales (TEI).

Palabras Clave: Cartas de emigrantes; Cartas privadas; Correspondencias; Normas de edición; Humanidades digitales; TEI.

The article takes the $25^{\text {th }}$ anniversary of Enrique Otte's letter edition to revise the praxis of this and later similar efforts. We analyze the archival repositories, establish different types of letters, and take on the various editorial practices. In the last part, editorial standards are proposed and we emphasize the need to embrace practices of digital humanities (TEI) for future editions.

KeYwords: Emigrant letters; Private letters; Correspondences; Edition guidelines; Digital humanities; TEI. 
WERNER STANGL

\section{Introducción}

Hace un cuarto de siglo desde que la publicación de las famosas Cartas privadas de emigrantes a Indias, 1540-1616 de Enrique Otte impactó en la historiografía hispanoamericanista. Se puede usar el calificativo de «impacto», porque es difícil imaginarse un colega que no las haya usado en sus estudios o talleres estudiantiles. Durante las investigaciones para mi tesis, ${ }^{1}$ al conversar con colegas, cuando mencioné cartas de emigrantes, la pregunta automática de un $90 \%$ fue «¿como aquellas de Otte?» y los $10 \%$ restantes afirmaron con gesto, sabedores. También en los prólogos de otras ediciones de cartas, la referencia y reverencia a Otte nunca puede faltar.

Sin embargo, el propósito de este artículo no es el de escribir un homenaje más — por bien merecido que fuese - al erudito historiador difunto en 2006. ${ }^{2}$ Más bien quiero presentar un «informe del estado de investigación», dando un repaso por la bibliografía de ediciones de cartas privadas transatlánticas, con algunos ejemplos anteriores a Otte y una creciente actividad editorial inspirada por su obra. Veremos las variadas fuentes de archivo en que se basan las ediciones de cartas, advirtiendo sobre las características de estas fuentes, las ventajas y desventajas de los diferentes cuerpos de cartas como fuentes históricas para investigaciones. Además, compararemos la contextualización de las cartas en las ediciones, las pautas y el rigor de las normas de edición, etc. Al finalizar, comentaremos sobre el potencial de los diferentes tipos de fuentes para futuras investigaciones y ediciones, y propondremos estándares y métodos al día para realizar tales esfuerzos.

Lo que no cabe en este artículo es repasar en detalle las líneas de aquellos estudios que analizan aspectos temáticos de cartas privadas transatlánticas, basándose en cartas editadas o inéditas. A grandes rasgos, los temas más recurrentes son la historia de género; lingüística; aspectos biográficos; redes de familia, poder y negocios; y cada vez más la historia de las comunicaciones. Especialmente con respecto a los lingüistas hay que constatar que el foco de interés en las cartas está muy concentrado en el siglo XVI, mientras que las cartas de las épocas más tardías fueron — de

1 Stangl, 2012

2 Domínguez Ortiz, 1990; Martínez, 1994; Vollmer, 2006. 
forma global - ignoradas. También en otros aspectos los estudios interesados en el siglo XVI son mucho más abundantes. ${ }^{3}$

\section{Ediciones de fuentes documentales y tipos de cartas privadas}

Las posesiones españoles en ultramar fueron un «imperio regido por cartas», como bien advirtió una vez Vicenta Cortés Alonso. ${ }^{4}$ Las cartas entre oficios, entre oficio y parte, de cabildo, etc. llenan los fondos del Archivo General de Indias y fueron objeto de las primeras ediciones de cartas compiladas por historiadores de los siglos XIX y XX, ${ }^{5}$ en las que solo ocasionalmente se encuentra alguna carta privada en la multitud de otro tipo de correspondencia. ${ }^{6}$

También se debe al interés en los protagonistas prioritarios de la Conquista y las primeras décadas siguientes que fueran editadas algunas de tales cartas como documentos con valor propio. Otra vez hay que resaltar a Enrique Otte como la persona más importante al respecto: con la edición de cartas de Diego Delgadillo, oidor de la primera Audiencia de México, y su hermano $;^{7}$ de su adversario, el arzobispo fray Juan de Zumárraga ${ }^{8}$ otras nueve cartas del conquistador Diego de Ordás, ${ }^{9}$ cuyas cartas complementan la imagen de su carácter pintada por los feroces ataques de Bartolomé de las Casas acerca de su actitud frente a los indígenas de Paria: ${ }^{10}$ algunas cartas de mercaderes vascos y burgaleses que seguían los pasos de los conquistadores; ${ }^{11} \mathrm{y}$ dos cartas de otros mercaderes menos importantes. ${ }^{12}$

3 Una excepción en el ámbito de la lingüística son los análisis de cartas castellano-catalanas por Cala, 1999; Cala, 2000/2001; Cala, 2003.

4 Cortés Alonso, 1984.

5 Ministerio, 1877; Paso y Troncoso, 1939-1942; Porras, 1959.

6 Altuna, 2000, presentó un estudio basado en una antología de las «cartas privadas» contenidas en Porras, 1959. Sobre el problema de definir y seleccionar «cartas privadas» a partir de contenido o formalidades (encabezamiento), ver Stangl, 2012, 79-92.

7 Otte, 1970, 95-111.

8 Lockhart y Otte, 1976, 207-210; Otte, 1978-1979. Ya Jiménez de Espada, 1885, había publicado 3 cartas familiares del obispo, pero no sacadas de actas procesales sino de un fondo privado.

9 Otte, 1964a. En el Archivo General de Indias (AGI), Justicia, 712, 1 se encuentran ocho cartas más de Ordás que no han sido publicadas.

10 Las Casas, 1552, 35.

11 Otte, 1964b; Otte, 1968a.

12 Publicadas en Lockhart y Otte, 1976, n. ${ }^{\circ} 14,86-113$ y n. ${ }^{\circ} 20,131-135$; sacadas de AGI, Justicia, 402, 2, 1 y AGI, Justicia, 1126, 3, respectivamente. 
Otras cartas sacadas de procesos seculares se encuentran en la compilación de Raúl Porras ${ }^{13}$ y tres más en un artículo de Genaro Rodríguez sobre el hacendado Hernando Gorjón en la Isla Española. ${ }^{14}$ En cuanto a cartas de este tipo se nota un punto principal en las primeras décadas - todas las cartas arriba mencionadas se escribieron entre 1520 y 1553 - y son de la sección Justicia del AGI en Sevilla. En cambio, de la mucho más extensa sección de Escribanía de Cámara de Justicia, donde se encuentran las actas de la justicia del Consejo en tiempos más tardíos, a mi saber solo se publicaron seis cartas, todas ellas del mismo proceso y de la década de $1550 .{ }^{15}$ Seguramente este focus se debe también al rico contenido de informaciones de toda índole que generalmente caracteriza a las cartas más tempranas por las inestables comunicaciones y el grado de novedad de muchas informaciones del Nuevo Mundo, ${ }^{16} \mathrm{y}$ aún más esto vale para las cartas de personas de importancia.

Más recientemente, en 2007, María del Carmen Martínez publicó una excelente edición de 277 cartas transatlánticas que cubren un período muy amplio — van de 1537 a $1819 —,{ }^{17}$ y una serie de cinco cartas decimonónicas fue publicada por Ana Gimeno. ${ }^{18}$ Ambas autoras sacaron las cartas del Archivo de la Real Chancillería de Valladolid, por lo que también éstas son vestigios de un grupo muy pequeño de personas que tuvo acceso a esa institución. Tanto las cartas de AGI, Justicia como las de la Real Chancillería cubren todos los territorios de la América española y todas las regiones peninsulares.

Lo mismo teóricamente se puede decir sobre cartas contenidas en los legajos de autos de bienes de difuntos, de las que a mi saber solo se han publicado cuatro. ${ }^{19}$ La razón hay que buscarla en la relativamente baja densidad de cartas en los autos - aproximadamente en el 10\% de los casos, según una prueba hecha al azar-. Además, los autos son muy voluminosos y el contenido de las cartas muchas veces se reduce exclusivamente a la noticia o confirmación de la muerte de una persona. Antonio García-

13 Porras, 1959, n. $^{\circ} 80,81,160$ y 303.

14 Rodríguez Morel, 1995. Dos de los documentos en el apéndice del artículo no son cartas privadas sino cartas de poder.

15 Porras, 1959, n. $^{\circ} 83,87,101,114,115$ y 120.

16 Stangl, 2013, 40 y $46-52$.

17 Martínez Martínez, 2007.

18 Gimeno, 2005.

19 Tres en García Abásolo, 1992, y una en Aramburu, 1999, n. ${ }^{\circ} 19$. 
Abásolo y María del Carmen Pareja hicieron uso de algunas cartas de esta fuente para dos artículos, pero citándolas y no editándolas enteras. ${ }^{20}$

Por supuesto, existe también una amplia documentación a escala regional o local en la que se pueden encontrar documentos similares. Se puede decir, y es casi una regla, que es en los ámbitos vasco y canario en los que existe el mayor interés en cartas privadas de emigrantes encontradas en archivos municipales o provinciales. En 1992 Jesús María Usunáriz publicó 241 cartas de emigrantes escritas entre 1696 y $1797,{ }^{21}$ sacadas de diversos archivos guipuzcoanos y navarros y de diversos fondos, la mayoría también relacionada con procesos seculares y eclesiásticos, entre ellos pleitos sobre herencias y fundaciones de capellanías. ${ }^{22}$ Mientras que esta edición tuvo eco entre los historiadores y se cita frecuentemente, no se puede decir lo mismo sobre las 91 cartas de navarros de los siglos XVI y XVII editadas por José Miguel Aramburu en 1999.23 A mi juicio, esta falta de recepción es inmerecida por la buena calidad de la edición y el rico contenido de las cartas.

Veintidós de las cartas de Usunáriz provienen de protocolos notariales. De este tipo de fuente tenemos también otras tres cartas de vascos de principios del siglo XVIII ${ }^{24}$ y una aislada carta de un emigrante montañés del valle de Toranzo. ${ }^{25}$ Es de esperar que archivos notariales en otras regiones de España también contengan correspondencias privadas muy extensas si solo en el caso navarro - región que no contribuyó con altas cifras a la emigración colonial, salvo en la segunda mitad del siglo XVIII- existe tanto material. Por lo menos para el Archivo Histórico Provincial de Tenerife está bien documentada la existencia de cartas privadas en actas de procesos y en protocolos notariales, y se han convertido en un pilar esencial de un estudio monumental de la emigración desde el noroeste de la ínsula entre 1750 y $1830 .{ }^{26} \mathrm{Un}$ caso especial son las 16 cartas de principios del siglo XVII entre un emigrante y su hermano en Castro del Río -ipor fin un ejemplo andaluz! - publicadas por Patricio Hidalgo. ${ }^{27}$ Aunque provienen de un archivo notarial, tienen una naturaleza bien diferente: no son

20 García Abásolo, 1989; Pareja, 1994.

21 Usunáriz, 1992.

22 Ibidem, 42-43.

23 Aramburu, 1999.

24 Pescador, 1996.

25 González Echegaray, 1979.

26 Rodríguez Mendoza, 2004.

27 Hidalgo, 2006. 
piezas probatorias y no pertenecen a ningún acto específico. El hijo del destinatario de las cartas fue notario en Córdoba y las depositó entre los protocolos, y podemos imaginarnos al notario, leyendo con interés estos documentos de su historia familiar en algún momento de ocio y luego colocándolas en una pila de actas.

Muy escasas son las ediciones de cartas transatlánticas sacadas de actas de procesos seculares en archivos americanos: a mi saber, el número se reduce a solo dos cartas del mercader Tomás Mañara al Perú (1614$1615)^{28}$ y a una serie de siete cartas al conquistador Alonso Díaz de la Reguera que fueron conservadas a causa de un proceso. Sin embargo éstas no se encontraron en un archivo público sino en uno privado que de alguna manera llegó a la Bancroft Library en Berkeley en 1991. ${ }^{29}$ La general preponderancia de cartas desde América a Europa en las ediciones coincide por supuesto con el mayor interés que nosotros los historiadores generalmente tenemos en informarnos a través de este tipo de fuentes más sobre las realidades americanas que sobre las europeas.

A la justicia secular, debemos también añadir la eclesiástica y la inquisitorial. Aquí cabe mencionar en primer lugar el libro El hilo que une, que contiene 231 cartas transatlánticas en ambas direcciones desde 1521 hasta 1783, junto con 136 cartas intra-americanas, encontradas entre los papeles del Tribunal del Santo Oficio en México. ${ }^{30}$ Las editoras también anunciaron una secuela de la edición con cartas de procesos ante el Tribunal de Lima, ${ }^{31}$ cuyos fondos hoy se dividen entre el Archivo Nacional de Perú, Lima, y el Archivo Histórico Nacional de Chile, Santiago de Chile, adonde se llevaron durante o poco después de la Guerra del Pacífico. ${ }^{32}$ Lamentablemente, aún 13 años después de la publicación la secuela no ha visto la luz del día.

Es casi imposible rescatar cartas de procesos ante el tribunal de Cartagena de Indias, cuyos fondos cayeron víctima de un incendio, aunque sí algunas están preservadas en el Archivo Histórico Nacional en Madrid, donde hay copias de muchos procesos de los tres tribunales americanos y donde he encontrado también copias de algunas de las cartas de El hilo que

28 Lohmann, 2004.

29 Cortijo y Cortijo, 2003.

30 Sánchez y Testón, 1999. Siete cartas más son correspondencia de la Inquisición y no califican como cartas privadas.

31 Ibídem, 15.

32 Guibovich, 2009. 
une y otras 31 cartas transatlánticas hasta ahora inéditas. ${ }^{33}$ Ya antes de Sánchez y Testón, Jesús González de Chávez había editado16 cartas de emigrantes canarios del siglo XVIII en los fondos del Santo Oficio en Gran Canaria. ${ }^{34}$ Hay que admitir que estas cartas, por interesantes que sean, son escritas de o a personas en una situación muy peculiar, generalmente siendo acusados de bigamia. Por esto este tipo de cartas, más que otros, desarrolla su verdadero valor como fuentes cuando se usan para el estudio de las vidas de los procesados, los procesos mismos o del delito de bigamia y no en ediciones que hacen escasa referencia al complejo material que rodea a las cartas. En mi tesis, he desarrollado un caso para ejemplificar la relevancia de la contextualización, revelando no solo que dos de las cartas fueron traducciones del italiano y originalmente no escritas en español, sino también que una carta fue identificada en el proceso como falsificación y sujeto de investigaciones escrupulosas. ${ }^{35}$

Conflictos al rededor de matrimonios también causaron otras querellas jurídicas que conducían a la conservación de cartas. Las Leyes de Indias impusieron severas normas para preservar la «vida maridable» y obligaron a los hombres casados a volver después de un período de unos pocos años en Indias o llamar a sus esposas que vinieran a vivir con ellos. Algunas mujeres se negaron a ir, otras simplemente ya no escucharon más de sus maridos y tenían que emplear personas de confianza para averiguar la residencia de los esposos. Con el material probatorio podían acudir al obispo de Cádiz (en el siglo XVIII; antes habrá sido el arzobispo de Sevilla, supongo) para reclamar la vuelta de sus maridos con una «requisitoria». María de la Pascua Sánchez editó 19 cartas de este tipo, encontradas en el archivo diocesano de Cádiz, en su interesante estudio sobre mujeres abandonas en Cádiz. ${ }^{36}$ Otro tipo de conflicto en este ámbito fueron procesos por

33 Procesos del Tribunal de México: Archivo Histórico Nacional (AHN), Inquisición, 1733, 12, «Proceso de fe de Francisco Alberto», 1661 (2 cartas inéditas además de aquellas que sí están en Sánchez y Testón, 1999); AHN, Inquisición, 1729, 5, «Proceso de fe de Antonio Chacón», 1699-1701 (1 carta); AHN, Inquisición, 1731, 35, «Proceso de fe de Francisco Antonio del Puerto Arriola», 1707 (5 cartas); AHN, Inquisición, 1730, 1, «Proceso de fe de Pedro de Mendoza y Escalante», 1725-1739 (17 cartas); procesos del Tribunal de Cartagena de Indias: AHN, Inquisición, 1622, 11, «Proceso de fe de Jorge del Barrio», 1694 (2 cartas); AHN, Inquisición, 1623, 2, «Proceso de fe de José Sainz de Aguirre», 1723-1724 (2 cartas); AHN, Inquisición, 1623, 6, «Proceso de fe de Ángel Antonio de Bustamante», 1777-1778 (1 carta); del Tribunal de Lima: AHN, Inquisición, 1648, 19, «Proceso de fe de Francisco de Castro», 1665-1670 (1 carta). Acerca de Pedro de Mendoza y Escalante ver Alfaro Ramírez, 1997.

34 González de Chávez, 1982.

35 Stangl, 2012, 70-78.

36 Pascua Sánchez, 1998. 
el incumplimiento de promesas matrimoniales, matrimonios celebrados en ausencia con poderes y pleitos de libertad para casarse de nuevo, intentados por mujeres que consideraban muerto a sus maridos ausentes. ${ }^{37}$

Muy similares a esas cartas son las famosas «cartas de llamada», término acuñado por Enrique Otte. Acerca de las particularidades de esta fuente ya me he detenido con más detalle en otra ocasión, ${ }^{38}$ por lo que me limito aquí a dar un corto repaso por la historia de las ediciones. Las primeras cartas de llamada ya fueron editadas en la inmensa colección de documentos para la historia de Chile recopilada por el historiador José Toribio de Medina en el siglo XIX, quien realmente debe haber revisado todo el archivo para también encontrar estos dos documentos aislados..$^{39} \mathrm{El}$ valor de las cartas para la historiografía fue formulado por primera vez a principios del siglo XX por Luis Rubio y Moreno en su estudio sobre las licencias de emigrantes, donde dijo:

Epistolario familiar se llamaría a una colección de cartas escritas por esposos, padres y deudos que figuran a la cabeza del expediente donde hoy se encuentran. Las hay ingenuas, afectivas, interesantes, con notas de negocios, costos de objetos o mercancías, quejas, avisos, menudencias y prevenciones, curiosas todas, son dignas de publicarse algunas, copiando solo las frases más salientes, si la copia total hubiera de resultar en extremo voluminosa. Las hay de individuos que proceden de todas regiones españolas y escritas algunas en catalán, valenciano, etc. ${ }^{40}$

Pero pasaría medio siglo más hasta que por primera vez Adolfo de Morales $^{41}$ y luego Enrique Otte ${ }^{42}$ se encargaran por primera vez de editar algunas de esas cartas. Todas ellas, y muchas más, componen el contenido de las 657 Cartas de emigrantes a Indias publicadas en 1988, que cubren el período entre 1540 y 1616.

El ya mencionado éxito masivo de la edición inspiró a otras, ampliando el alcance cronológico: En 1991 se publicaron 226 cartas de llamada del siglo XVIII por Isabelo Macías y Francisco Morales Padrón —otra edición que hizo eco- ${ }^{43}$ Ya menos conocidas son las ediciones más tardías: en

3734 y 20 cartas, respectivamente, en Usunáriz, 1992, todas del Archivo Diocesano de Pamplona.

38 Stangl, 2010

39 Medina, 1898, n..$^{\circ}$ XVII y XXVIII. Las cartas están también en Otte, 1988, n. ${ }^{\circ} 619$ y 620.

40 Rubio, 1930, 23. El trabajo ya había sido publicado antes, alrededor de 1920, sin año.

41 Morales, 1964. Las seis cartas se reeditaron en Otte, 1988.

42 Otte, 1966; Otte, 1968b; Otte, 1969.

43 Macías y Morales, 1991. 
1994 apareció una colección, algo obscura, por Rosario Márquez Macías con 149 cartas de emigrantes de fines de la colonia (1768-1824), de las que 29 ya habían sido publicadas por Macías y Morales. ${ }^{44}$ Aparentemente la editora ya había conocido el material antes de las Cartas de emigrantes a Indias, como indica una pequeña edición de tres cartas en un artículo de $1988 .{ }^{45}$ En 2001 siguió otra pequeña edición de 24 cartas de llamada de Puerto Rico por la misma autora. ${ }^{46}$

A su vez, María Dolores Pérez Murillo publicó 14 cartas de llamada de emigrantes vascos desde $\mathrm{Cuba}^{47}$ y luego un total de 93 cartas de cartas escritas desde Cuba de 1800 a 1829.48 También en estas ediciones hay solapaduras considerables con las ediciones anteriores de Márquez. Además, hay que mencionar las 22 cartas de principios del siglo XVII editadas por Auke Jacobs en 1995, que no son muy conocidas puesto que se esconden en forma de apéndice en un estudio sobre la migración durante el reinado de Felipe III. ${ }^{49}$

Fue el celo de desanudar el caos, de averiguar el grado de integridad del material publicado, corregir los errores más graves de otras ediciones y de completar lo que faltaba el que me condujo a revisar todos los fondos con licencias de embarque en el AGI. El resultado de estos esfuerzos es una edición de un total de 1214 cartas, de las que 1153 eran inéditas y las restantes cartas editadas de nuevo por razones de calidad o integridad del documento. ${ }^{50} 52$ de las cartas inéditas son de antes de 1616 y aparentemente se escaparon a la atención de Otte (se puede decir sobre 41 cartas del siglo XXVIII en el caso de Macías y Morales Padrón para la serie de licencias en AGI, Contratación). Un número muy reducido de doce cartas son de fines del XVII, una época ignorada por las demás ediciones, mientras que la gran mayoría con más de mil cartas cubre los años entre 1787 y 1824.

Todas las cartas de llamada arriba mencionadas se encuentran en el AGI, pero cabe mencionar que diversos archivos municipales también contienen cartas de este tipo, ya que fue en los lugares de origen donde se formaron las informaciones necesarias para lograr las licencias de embarque.

44 Márquez, 1994.

45 Márquez, 1988.

46 Márquez, 2001.

47 Pérez Murillo, 1996.

48 Pérez Murillo, 1999.

49 Jacobs, 1995.

50 Edición completa: Stangl, 2012, suplemento electrónico. Una antología de 200 cartas especialmente interesantes se encuentra en el tomo impreso como apéndice. 
Ángel Mari Arrieta incluye dos cartas de llamada de 1817 y 1818, sacadas de licencias en el Archivo Municipal de Llodio, en su estudio sobre la emigración alavesa en el siglo XIX, ${ }^{51}$ y cinco de las cartas publicadas por Usunáriz del Archivo de Protocolos de Navarra también son de este tipo. ${ }^{52}$

Tanto cartas de llamada como aquellas de procesos de toda índole, requisitorias, autos de bienes de difuntos o protocolos notariales son asociadas con algún acto público que condujo a su presentación ante un oficial y su conservación. Pero existe un volumen mucho mayor de cartas en archivos personales o privados, o en fondos privados legados a archivos públicos. Estos repositorios se distinguen de los otros especialmente por contener no solo cartas aisladas o un número muy reducido de cartas de una correspondencia, sino muchas veces todas las cartas que iban a una parte, y hasta a veces correspondencias enteras en ambas direcciones.

Los archivos privados y familiares sufrían, mucho más que los públicos, pérdidas de fondos a causa de imponderabilidades a través del tiempo, por lo que solo pocos archivos antes del siglo XIX sobrevivieron, muchos de ellos en algún momento transferidos a un archivo público, como la Sección Nobleza del Archivo Histórico Nacional (AHN) en Madrid o archivos regionales y locales. Ya que de muchas familias nobles hubo miembros que pasaban a Indias en algún momento, es bastante frecuente encontrar sus correspondencias en los fondos. El mayor problema con respecto a esas correspondencias es el extremo estrechamiento a las capas más altas de la sociedad, muy conscientes de su tradición familiar. ${ }^{53}$ Para los siglos XVI y XVII los archivos privados se limitan casi totalmente a la Alta Nobleza, y también para el siglo XVIII el estrato social que logró conservar sus documentos hasta hoy no es mucho más largo. La gran mayoría de esas correspondencias ha sido hasta ahora ignorada, algunas servían como fuente principal para diversos estudios, y se puede contar con los dedos de una mano aquellas editadas. Interesantemente todas estas cartas son del siglo XVII o los primeros años del XVIII, un período generalmente menos presente en la mayoría de ediciones de archivos públicos.

La única correspondencia transatlántica editada del AHN-Nobleza que he logrado identificar es la de Gelvira de Toledo, esposa del virrey de Nueva España Conde de Galve, que contiene 27 cartas. ${ }^{54}$ En el ámbito

51 Arrieta, 1992.

52 Usunáriz, 1992, n.․ 229, 233, 234, 240 y 241.

53 Castillo Gómez, 1997, 222.

54 Dodge y Hendricks, 1993. 
regional o local, la situación es similar: tenemos una serie de 48 cartas del re-conquistador de Nuevo México, Diego de Vargas, sacadas de archivos privados en Madrid ${ }^{55}$ recientemente, Adolfo Arbelo ha publicado una recopilación de 186 cartas sacadas de diversos fondos privados y familiares depositadas en varios archivos canarios; ${ }^{56}$ además tenemos tres cartas de Rafael Carvajal, un noble de Antequera, Andalucía; ${ }^{57}$ ocho cartas particularmente interesantes del noble gaditano Rafael de Sopranis del Archivo Pérez-Lila de Sopranis en Jerez de la Frontera; ${ }^{58}$ y cartas de catalanes editadas en una tesis doctoral. ${ }^{59}$

El único otro grupo del que sobrevivió documentación privada de notable número son de mercaderes ilustres. En el archivo de Simón Ruiz en Medina del Campo existe un número reducido de 61 cartas de América de las que a mi saber se han publicado tres: una de un minero en la Villa Imperial de Potosíi ${ }^{60}$ y dos de comerciantes arraigados en México. ${ }^{61}$ En el AGI, Consulado, existen 68 legajos con correspondencias de una docena de individuos. ${ }^{62}$ Estas correspondencias extensas se han usado con frecuencia para reconstruir redes personales de mercaderes, ${ }^{63}$ pero solo 28 cartas familiares escritas a Tomás Ruiz de Apodaca — de más de 1800 cartas de y a este personaje que se encuentran en el archivo- se han publicado en su totalidad. ${ }^{64}$ José María Imízcoz, quien estudia las redes de las élites vasco-navarras en la Monarquía española, juzgó que «los trabajos con cartas sueltas (Otte, Usunáriz)» no tienen la misma capacidad para analizar «dinámicas internas, lógicas, duración» como tienen las

55 Kessell, 1989.

56 Arbelo, 2010.

57 López, 1961. López no identifica el origen exacto de las piezas de correspondencia, pero queda claro que el material fue sacado de fondos privados.

58 Solano, 1992. Son nueve documentos, pero el documento 8 no es una carta privada.

59 Cala, 1999. Lamentablemente la tesis es inédita y no he logrado examinarla.

60 Helmer, 1956. Helmer, 1967, analiza todo el corpus sin editar las cartas.

61 Carande, 1944.

62 Tomás Ruiz de Apodaca, AGI, Consulado, 397-405 y 772-774; Adrián de Elosu, 406-407; Galdona e Ibarburu, 408-415B; Lorenzo López de Ezeiza, 416; Andrés de Fraga, 417; Norberto Michelena, 418; Francisco García de Padin, 419; Francisco Sierra, 420-428; Juan Francisco Puch, 429; Esteban de Acuña, 430-431; Juan Vicente Marticorena/Pedro Fermín de Córdoba, 432-439; Antonio de Artechea, 440-463; personas del navío La Constanza, 464.

63 Usando cartas de AGI, Consulado: Hausberger, 2004; Arroyo, 2007; Baskes, 2011. Usando correspondencias de otros archivos para estudios de redes mercantiles o de élites: Imízcoz, 2001; Angulo, 2002; Testón y Sánchez, 2002; Moutoukias, 2003; Lamikiz, 2007; Lamikiz, 2010; Hernández González, 2010. Indudablemente, se podría extender la lista.

64 Garmendia, 1989. 
correspondencias compactas. ${ }^{65}$ Aún así, casi todas las ediciones publican «cartas sueltas».

¿Acaso hemos editado las cartas desacertadas? Creo que no: es absolutamente lógico que para estudios relacionales o biográficos sirva extractar el contenido de un conjunto de correspondencia, reproducir algunas citas concretas y analizar cuantitativamente la intensidad de contactos entre corresponsales, las jerarquías y otros aspectos, sin necesidad de reproducir los documentos enteros. Las ediciones de cartas, en cambio, sirven para otro propósito: son minas de información para ser explotadas por un número máximo de historiadores y filólogos y hasta por genealogistas. Y para esta función sirven más colecciones con un alto número de voces independientes y de estratos sociales menos limitadas en comparación con correspondencias que giran alrededor de un núcleo limitado de gente.

La siguiente tabla enumera todas las ediciones de cartas privadas transatlánticas hasta el año 1824 que he logrado encontrar.

\section{TABLA 1}

EDICIONES CON CARTAS PRIVADAS TRANSATLÁNTICAS, 1492-182466

\begin{tabular}{|c|c|c|c|}
\hline Edición & \# total & Período & Tipo de archivo/fondo \\
\hline Stangl, 2012 & 1213 & $1558-1822$ & Licencias de embarque \\
\hline Otte, $1988^{67}$ & 657 & $1540-1616$ & Licencias de embarque \\
\hline Martínez, 2007 & 277 & $1537-1819$ & Jurídico (procesos) \\
\hline
\end{tabular}

65 Así lo había formulado en la descripción de su proyecto «A la sombra de la Corona: las elites vasco-navarras ...» que hasta hace poco fue accesible en la página web de la Universidad del País Vasco. Lamentablemente la página ya no existe.

66 No se incluyen cartas «privadas» de jesuitas, por no poder tematizar aquí los discursos en los que se deben embutir tales documentos y por la extensa bibliografía que merecería un propio estudio. Las cartas de jesuitas a sus familiares son muchas veces verdaderas relaciones sociológicas o etnológicas, como aquella del jesuita bávaro Franz Rauber a su hermana del 16 de julio 1731 desde Cartagena de Indias, que es una relación de 32 folios de su viaje, de la sociedad de castas, la esclavitud, el consumo del chocolate en Nueva Granada y muchos otros temas. El original - en contra del título está escrito en alemán - se encuentra en la Biblioteca Nacional de Austria. Österreichische Nationalbibliothek (ÖNB), Cod.han., 5691: Relatio sui itineris et descriptio Novae Granatae, a. 1731. Tampoco se incluyen cartas escritas por personajes muy destacados, como Cortés y los Pizarro, y sus familiares. Algunas ediciones más recientes de cartas en estos ámbitos son las de Martínez Martínez, 2003; y Martínez Martínez, 2006.

67 En la tabla no incluimos aquellas ediciones que exclusivamente contienen cartas editadas en Otte, 1988: Morales, 1964; Otte, 1966; Otte, 1968b; y Ruiz, 2003. Sin embargo, las tres últimas son de interés por contener transcripciones más cercanas a los originales. 


\section{TABLA 1 (continuación)}

EDICIONES CON CARTAS PRIVADAS TRANSATLÁNTICAS, 1492-1824

\begin{tabular}{|c|c|c|c|}
\hline Edición & \# total & Período & Tipo de archivo/fondo \\
\hline Usunáriz, 1992 & 241 & $1696-1797$ & $\begin{array}{l}\text { Jurídico (procesos; protocolos } \\
\text { notariales) }\end{array}$ \\
\hline Sánchez y Testón, $1999^{68}$ & 231 & $1521-1783$ & $\begin{array}{l}\text { Jurídico (procesos de } \\
\text { Inquisición) }\end{array}$ \\
\hline Macías y Morales, $1991^{69}$ & 226 & 1700-1799 & Licencias de embarque \\
\hline Arbelo, 2010 & 186 & 1744-1796 & Fondos personales \\
\hline Márquez, 199470 & 148 & $1768-1824$ & Licencias de embarque \\
\hline Aramburu, $1999^{71}$ & 91 & $1556-1708$ & Jurídico (procesos) \\
\hline Pérez, 199972 & 74 & $1800-1824$ & Licencias de embarque \\
\hline Kessell, 1989 & 48 & $1675-1706$ & Fondo personal \\
\hline Garmendia, $1989^{73}$ & 28 & $1759-1766$ & Fondo personal \\
\hline Dodge y Hendricks, 1993 & 27 & 1689-1696 & Fondo personal \\
\hline Jacobs, $1995^{74}$ & 22 & $1589-1618$ & $\begin{array}{l}\text { Licencias de embarque } \\
\text { y jurídico (procesos) }\end{array}$ \\
\hline Porras, $1959^{75}$ & $\sim 20$ & $1527-1542$ & Jurídico (procesos) \\
\hline Pascua, 1998 & 18 & 1739-1792 & Jurídico (requisitorias) \\
\hline González, 1982 & 16 & $1712-1798$ & $\begin{array}{l}\text { Jurídico (procesos de } \\
\text { Inquisición.) }\end{array}$ \\
\hline Hidalgo, $2006^{76}$ & 16 & $1608-1636$ & $\begin{array}{l}\text { Jurídico (protocolos } \\
\text { notariales)/Privado }\end{array}$ \\
\hline Otte, $1968 \mathrm{a}$ & 14 & $1520-1524$ & Jurídico (procesos) \\
\hline
\end{tabular}

68 Además, en la edición se editan 136 cartas intra-americanas.

69 Una carta, n. ${ }^{\circ}$ 131, fue reeditada en Stangl, 2012, porque en Macías y Morales, 1991, falta la posdata.

70 Uno de los 149 documentos no se califica como carta privada. 29 cartas ya habían sido editadas antes en Macías y Morales, 1991; 25 posteriormente en Pérez, 1999; 46 en Stangl, 2012; y 4 cartas más están en las tres ediciones Márquez, 1994; Pérez, 1999; y Stangl, 2012.

71 La edición incluye unas pocas cartas intra-americanas.

7219 cartas más de la edición fueron escritas entre 1825 y 1839 , por lo que no figuran en la tabla. Para las solapaduras con Márquez, 1994, ver nota 67. 8 cartas más fueron reeditadas en Stangl, 2012.

73 En la edición es a veces difícil distinguir donde termina una carta y donde empieza otra, por lo que el número de 28 es solo un acercamiento.

74 Una carta (n. ${ }^{\circ}$ 4) es idéntica con una de la edición de Otte, 1988, n. ${ }^{\circ} 258$.

75 Algunas cartas privadas fueron ya editadas en ediciones anteriores, como Jímenez, 1877, y no se incluyen aquí. El número de cartas privadas en la colección no se puede indicar con exactitud por los problemas metodológicos ya mencionados.

76 El libro contiene más cartas, pero intra-españolas. 
WERNER STANGL

TABLA 1 (continuación)

EDICIONES CON CARTAS PRIVADAS TRANSATLÁNTICAS, 1492-1824

\begin{tabular}{lrll} 
Edición & \# total & Período & \multicolumn{1}{c}{ Tipo de archivo/fondo } \\
\hline Márquez, 200177 & 14 & $1787-1813$ & Licencias de embarque \\
Solano, 1992 & 8 & $1642-1673$ & Fondo personal \\
Cortijo y Cortijo, 2003 & 7 & $1540-1548$ & Jurídico (procesos)/ \\
& & & fondo personal \\
Gimeno, 2005 & 5 & $1818-1824$ & Jurídico (procesos) \\
Jiménez, 1885 & 3 & $1539-1541$ ? & Fondo personal \\
López, 1961 & 3 & $1633-1638$ & Fondo personal \\
Otte, 1970 & 3 & 1529 & Jurídico (procesos) \\
Lockhart y Otte, 1976 ${ }^{78}$ & 3 & $1548-1553$ & Jurídico (procesos) \\
Márquez, 1988 & 3 & $1810-1824$ & Licencias de embarque \\
García, 1992 & 3 & $1628-1630$ & Jurídico (Autos de bienes \\
& & & de difuntos) \\
Rodríguez, 1995 & 3 & 1542 & Jurídico (procesos) \\
Pescador, 1996 & 3 & $1700-1708$ & Jurídico (protocolos notariales) \\
Otte, 1964b & 2 & $1525-1526$ & Jurídico (procesos) \\
Pérez, 1996 & 11 & $1802-1824$ & Licencias de embarque \\
Carande, 1944 & 2 & 1568 & Fondo personal \\
Lohmann, 2004 & 2 & $1614-1615$ & Jurídico (procesos) \\
Helmer, 1967 & 1 & 1595 & Fondo personal \\
Otte, 1978-1979 & 1 & 1540 & Jurídico (procesos) \\
González, 1979 & 1 & 1598 & Jurídico (protocolos notariales) \\
Arrieta, 1992 & 1 & $1817-1818$ & Licencias de embarque \\
Earle, 2003 & 1 & 1823 & desconocido (censura?) \\
& & &
\end{tabular}

Elaboración propia. Tabla modificada de Stangl, 2012, 94-95.

77 Solo la carta n. ${ }^{\circ} 8$ no se puede encontrar en otra edición. Las otras 13 cartas fueron reeditadas en Stangl, 2012. Diez cartas (n. $\left.{ }^{\circ} 15-24\right)$ fueron escritas después de 1824 y no figuran en la tabla.

78 N. ${ }^{\circ} 14,20$ y 33 , traducidas al inglés.

79 Zwei der drei dort publizierten Briefe wurden für diese Arbeit erneut transkribiert.

80 Solo la carta de Juan Ignacio Eguilelor a su primo Ignacio Recalde, La Habana, 2 de mayo 1802, no está en otra edición. 9 cartas están también en Márquez, 1994; Pérez, 1999 o Stangl, 2012. 3 fueron escritas después de 1824 y no figuran en la tabla. 


\section{Prácticas de edición (normas y calidad)}

Un aspecto que más me ha llamado la atención al hacer uso de las cartas de emigrantes fueron las muy diversas prácticas de edición, las normas para la transcripción, presentación, selección, documentación, etc. Transcribir no es una simple tarea mecánica, es también un acto interpretativo que quita, agrega y transforma un documento original. Reproduzco aquí lo que un diplomático ha advertido en cuanto a la edición de documentos originales:

El acercamiento al documento hay que entenderlo desde una perspectiva globalizadora que considera complementarios e integra todos los aspectos parciales de la manuscrita (aspectos paleográficos, gráficos, lingüísticos, históricos-culturales, etc.) para llegar a la total interpretación del texto. ${ }^{81}$

Como he argumentado, la utilidad de ediciones yace en su utilización por una amplia gama de personas con los más diversos intereses. Las ediciones deben tener en cuenta esto a la hora de su realización y tienen la responsabilidad de hacer totalmente transparente los criterios empleados. En este apartado voy a examinar y comparar las normas de las ediciones más importantes (con más de 20 cartas).

Sobre todo la modernización de la ortografía en Otte, 1988, ha causado críticas por el filólogo Manuel Alvar, quien se quejó de que

esas cartas habían sido transcritas en un libro apasionante donde los haya, pero su valor se aminoraba mucho al resultar inservible para el estudio de la lengua. Enrique Otte en la transcripción de esas 650 cartas privadas, como en otros trabajos suyos, se había desentendido de lo que más nos interesa a nosotros y a la historia americana. ${ }^{82}$

En mi opinión, hay que absolver al profesor Otte: sus ediciones anteriores de los años 1960 y 1970 son todas fieles a la ortografía original y muestran que la razón de su falta no puede haber sido ignorancia. Hay que culpar más bien al espíritu de la época: aparentemente Otte enfrentó resistencias que le impidieron seguir con su práctica habitual, o así se desprende de una mención de la filóloga Concepción Company: «Lástima que, por tristes experiencias anteriores, no se haya animado el Profesor Otte a respetar escrupolosamente [sic] la ortografía de los documentos, impidiendo

81 Andonegi, 2006, 426.

82 Alvar, 1994, sin paginar. 
así hacer estudios de carácter fonético sobre ellos» ${ }^{83}$ Dos filólogos jóvenes han basado sus tesis en grandes partes en re-transcripciones de las cartas de Otte, por lo que hoy en día ya disponemos de transcripciones más fieles de todas las cartas contenidas en Otte. ${ }^{84}$

También las ediciones de Macías y Morales, 1991, y Pérez, 1999, se modernizaron con respecto a esto. Alvar tiene razón: estas modernizaciones descalifican las ediciones para algunos usos académicos: oscurecen informaciones fonéticas, sobre el grado de alfabetización, sobre el dominio del idioma, etc. ${ }^{85}$ Pero tienen la innegable ventaja de asumir la tarea de «traducción» para el lector y contribuyen así a la difusión también entre gente no especializada.

Las ediciones de las cartas de Diego de Vargas y de la condesa de Galve así como la de cartas de llamada por Jacobs ${ }^{86}$ siguen un paradigma al otro extremo: tratan de ser fiel no solo a la ortografía, sino también a la puntuación, a los acentos y al uso de mayúsculas ${ }^{87}$ Aún así, Jerry Craddock, un lingüista de Berkeley, advirtió que la normalización de u/v y la decisión de transcribir no conservando la estructura de líneas del original en la edición de Kessell no coinciden con las normas de edición del Hispanic Seminary of Medieval Studies ${ }^{88}$ De las ediciones analizadas, solo las de Usunáriz, Aramburu y Martínez Martínez conservan la u/v del original.

A mi entender, estandarizar mayúsculas es muy aconsejable para las ediciones de cartas, ya que en muchas letras coloniales simplemente no hay forma de distinguir bien entre mayúsculas y minúsculas. Además, a algún autor simplemente le gustaba una mayúscula, por lo que brinda a cada palabra con esa letra inicial. Jacobs va a tal extremo que transcribe palabras como «entieRo» ${ }^{89}$ haciendo no solo muy difícil la lectura de las cartas, sino ignorando que la supuesta «R» es simplemente la ligatura para «rr». ${ }^{90}$ Además, el esfuerzo para conservar las mayúsculas se revela como deses-

83 Company, 1994, XIV, nota.

84 Ruiz, 1993; Fernández, 2009.

85 Ver Cala, 2000/2001. En muchas cartas de catalanes y vascos publicadas en Stangl, 2012, se pueden notar interferencias de las lenguas maternas en cartas escritas en castellano.

86 Kessel, 1989; Dodge y Hendricks, 1993; y Jacobs, 1995.

87 Kessell, 1989, así como Dodge y Hendricks, 1993, sin embargo, a veces completan arcaísmos usando cursivas cuando falta solo una letra (a[h]ora/ahora).

88 Craddock, 2003, 5. Aunque, revisando la edición de Kessel, sí parece que conserva la estructura de líneas.

89 Jacobs, 1995, n. $^{\circ} 15$.

90 Ver al respecto Rumeu de Armas, 1989, 433-434. 
perado cuando solo se dispone de una ínfima muestra de una letra individual en forma de un documento corto como es una carta. Por esta causa, tal vez es factible para correspondencias compactas, pero no para ediciones de «cartas sueltas». También en el aspecto de las mayúsculas Craddock cortó algunas decisiones editoriales de Kessell. ${ }^{91}$

El cauce común de la mayoría de las ediciones es respetar la ortografía, pero con consecuente modernización en los demás aspectos, justificado por lo general también con la «legibilidad», ${ }^{92}$ ya que es verdad que la lectura de las ediciones arriba mencionadas no es mucho más fácil que la de los originales. Pero opino que la modernización de estos aspectos se debe sobre todo a la necesidad de estructurar el texto y darle sentido en el proceso mismo de transcripción. En la gran mayoría de las cartas originales no se ponen acentos y no está estructurado el texto con comas o puntos. La estructura de ciertas cartas es a veces tan corta que ni se puede decir dónde termina una palabra y donde empieza otra o, al contrario, palabras se desgarran en medio, etc. Reconstruir las palabras o «unidades de sentido» es algo que nadie evita al transcribir.

Por razones obvias, esta intersección es una fuente natural e inevitable para muchos errores. Quiero presentar algunos ejemplos tomados de ediciones de cartas de llamada, pues son aquellas para las que me ha sido posible comparar la edición y el original. Otte por ejemplo transcribe una vez «razón lo hable» en vez de «razón lo[h]able»; ${ }^{3}$ Jacobs hace de «lo han de dar» «lo hande dar»;94 y en Macías y Morales la admonición «el mucho recato que se necesita en una muger por caminos de tierra» se transforma en un texto bien opaco: «el mucho recato que se necesita de una amuga por caminos» ${ }^{95}$ Las ediciones de Márquez, 1994, y Pérez, 1999, son especialmente deficientes. ${ }^{96} \mathrm{La}$ una pretende respetar la ortografía original y la otra la moderniza, pero si se comparan las transcripciones con los originales se puede notar en ambas que frecuentemente se modernizan arcaísmos. Además se arcaízan palabras con ortografía «normal» en el original, resultado de poca prudencia en la transcripción.

91 Craddock, 2003, 6.

92 Otte, 1964a, 102: «para facilitar la lectura»; Morales, 1964, 212: «facilita la arcaica construcción de las frases».

93 Otte, 1988, n. $^{\circ} 276$.

94 Jacobs, 1995, n. $^{\circ} 1$.

95 Macías y Morales, 1991, n. 37.

96 En Stangl, 2012, 309-314, se pueden comparar algunas transcripciones. 
Estas dos ediciones destacan también porque ocultan que las cartas editadas no constituyen el total encontrado en un fondo, sino que fueron seleccionadas por criterios desconocidos. En el caso de Pérez el acto de selección no parece tan grave porque la autora enfatiza la naturaleza decididamente cualitativa de su libro, en el que cada carta es acompañada de un corto texto que alumbra el caso individual. En la edición de Márquez, en cambio, casi no hay cartas de Nueva España — no porque no las haya, sino porque Márquez había ignorado los fondos- . No obstante, la autora no menciona esta falta de representatividad: más bien incluye en la edición algunas tablas y estadísticas cuantitativas, que por supuesto carecen de valor sin material representativo en que apoyarse (es más, la misma laguna para Nueva España es notable en su estudio cuantitativo de la emigración a partir de 1765). ${ }^{97}$

Otra forma de selección es no reproducir algunas partes de cartas que no contienen información «relevante». Es un fenómeno conocido que la densidad de información en las cartas es generalmente baja - Plummer ha acuñado la expresión dross rate (tasa basura) ${ }^{98}$ al respecto-, por lo que es comprensible que se quieran quitar las generalidades de saludos, despedidas u otros elementos repetitivos para no inflar el volumen de la publicación. ${ }^{99}$ Sin embargo, se debe tener mucho cuidado con intervenciones tan graves a causa del peligro de hacer una censura tácita por preferencias subjetivas.

La única edición de cartas transatlánticas en la que no se reproducen partes de cartas de forma deliberada es la de Pérez. Ahí, estas pretericiones, que a veces son de varios párrafos, se marcan solo con «(...)» y no se distinguen de lagunas cortas en el texto. En el caso de la edición de Macías y Morales es similar: partes ilegibles del texto se marcan con un simple «(roto)», que a veces se refiere solo a una parte de una palabra («con la ampl (roto) de» para «con la amplitud de») ${ }^{100} \mathrm{y}$ otras a un párrafo completo. ${ }^{101}$

Generalmente sorprende el grado de individualidad en las prácticas de intervenciones editoriales. En la mayoría de las ediciones se usan paréntesis «( )» en vez de las corchetes «[ ] y y no se utiliza acotación tipográfica (cursiva). Esto es un proceder muy problemático, puesto que el uso de

97 Márquez, 1995. Definitivamente sería muy útil un nuevo estudio para subsanar este déficit.

98 Plummer, 1983, 21-24.

99 Para los elementos típicos repetitivos especialmente en las cartas transatlánticas, ver Martínez Martínez, 2007, 39-46; y Arbelo, 2010, 30-21.

100 Macías y Morales, 1991, n. ${ }^{\circ} 19$.

101 Ibidem, n. ${ }^{\circ} 211$ termina «(roto) La Habana y septiembre (roto) de 1774 (roto)». 
paréntesis no es desconocido por los autores de las cartas, causando incertidumbre en algunos casos si un texto entre paréntesis es parte del original o intervención editorial. En Macías y Morales algunos comentarios simplemente se insertan en el texto ni siquiera con paréntesis: $«[\ldots]$ todo de guajaca (sic)-.Oaxaca-, $[\ldots] \gg .{ }^{102}$ Pérez también inserta de forma inflacionista adiciones propias con paréntesis en el texto - «[...] no puedo (enviarte) más $[\ldots]$ no seas omisa sino anda de los pies (date prisa) para $[\ldots] \gg,{ }^{103}$ pero también pone paréntesis simplemente en vez de coma para estructurar el texto original.

Ante estas incongruencias aparentemente no sobra mencionar que una de las exigencias más importantes para cualquiera edición es la prudencia en cuanto a la acotación y precisión de las propias intervenciones: algo «ilegible» no es algo «roto», hay que diferenciar limpiamente entre una laguna $(\ll[\ldots] »)$ y una lectura insegura $(«[?] \gg)$, y existe una diferencia entre una laguna de una parte de una palabra y una laguna que se extiende varias líneas o párrafos.

Un elemento en el que las intervenciones en las ediciones son ubicuas y muchas veces inconsecuentes y tácitas es la línea de fecha y lugar. Hasta mediados del siglo XVIII, lugar y fecha se pusieron casi exclusivamente al final de la carta, antes de la rúbrica, mientras que a partir de los años 1780 empezó a dominar el colocar estos datos en la cabecera. En las ediciones no siempre se limita a representar esta información tal como está en el original, sino que hay diversas prácticas de acercarse al tema: Otte por ejemplo transcribe el original pero también pone fecha/lugar en la cabecera de la carta. No acota esta información de la propia transcripción tipográficamente (usando por ejemplo cursiva), pero sí usa una forma estándar («Panamá, 24.IV.1581»), así dejando claro que se trata de una adición editorial. En los pocos casos en que la fecha en el original se encuentra en la cabecera de la carta, hay alguna confusión en el método: algunas veces el texto original simplemente se remplaza por la forma estándar, ${ }^{104}$ otras veces se repite. ${ }^{105}$

102 Ibidem, n. $^{\circ}$ 49. Corchetes en cursiva identifican intervenciones mías en este párrafo para no causar aún más confusiones.

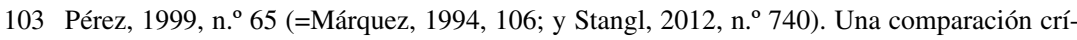
tica de las tres transcripciones en Stangl, 2012, 309.

104 Por ejemplo Otte, 1988, n. ${ }^{\circ}$. La carta en el original (AGI, Indiferente, 2051, n.3) empieza «P el s.or Ju.n Myn. / señor / de mexi.o a 15 de mayo de 1556 a.s», mientras que en Otte: «México, 15.V.1556 / Señor».

105 Por ejemplo Otte, 1988, n. $^{\circ} 15$. 
En la edición de Garmendia, 1989, fecha/lugar aparentemente se reproducen de forma estandarizada antes del documento, pero la práctica no es consecuente en hacerlo. Además, los documentos ni siquiera están numerados. Así es imposible averiguar el número exacto de cartas diferentes en la edición, porque es común que un autor continúe una carta en otro día poniendo nueva fecha, o que copie su carta anterior (en caso de no haber llegado), o que otra persona agrege su carta en el mismo papel. Jacobs a su vez también repite fecha/lugar al inicio sin acotación, pero no en forma estandarizada, lo cual causa confusión. Pérez y Arbelo tácitamente quitan fecha/lugar de la transcripción y colocan la información en la parte descriptiva del documento. Macías y Morales normalmente transcriben fecha/lugar como en el original, pero no lo hacen siempre; sin razón aparente, en unas pocas cartas trasplantaron tal elemento a otro lugar de la carta, generalmente de la cabeza al pie. ${ }^{106}$ Márquez hace este trasplante de forma genérica — contrario a la práctica en la época-.

Las intervenciones en este aspecto son especialmente propensas a errores. ${ }^{107}$ En Macías y Morales el trasplante causó una equivocación en la fecha en tres ocasiones, ${ }^{108}$ y en Márquez, quien pretende conservar la ortografía, una carta que en el original empieza «Sra Da Tereza Ojeda. Lima y 8bre 13 de 812» en la edición termina con «Señora Doña Teresa Ojeda, Lima y septiembre [sic] 13 de 1812». ${ }^{109}$

Llegamos al último aspecto en este apartado: la metainformación de las cartas. Ésta se debe orientar al tipo de cartas que se editan. En cartas de correspondencias compactas, la metainformación idealmente incluye informaciones biográficas más extensas, mientras que en ediciones de cartas sueltas muchas veces no hay información suficiente en este aspecto. Por esta causa, generalmente se limita a una cabecera estandarizada con el nombre del autor, destinatario, fecha y lugar sin muchas notas a pie con respecto a nombres mencionados en el texto. Lo mínimo debe ser la indicación del repositorio de los documentos. Como no puede ser de otra forma,

106 Por ejemplo Macías y Morales, 1991, n. ${ }^{\circ} 74,81,82,86$ y 87.

107 Generalmente, los nombres propios de personas y lugares son ya por sí una fuente común en todas las ediciones, lo que hace a veces la ínfima diferencia entre «Guaira» (Márquez, 1994, 51-52) y «Guatemala» (Macías y Morales, n. ${ }^{\circ}$ 104) - el original dice «Guath. ${ }^{\circledR} »$ (AGI, Contratación, 5520, 1, 31, expediente de Francisco José Palomo). En Stangl, 2012, 315-320, se encuentran corrigenda para un buen número de errores en las demás ediciones de cartas de llamada.

108 Macías y Morales 81, 82 y 87.

109 Márquez, 1994, 136. Las cartas en Márquez ni tienen numeración. 
en la edición de Márquez, ni encontramos este requisito mínimo, pero durante mis propias investigaciones en el AGI he logrado identificar el repositorio de la mayoría de las cartas. ${ }^{110}$ Habría que mencionar que también en la edición de Otte en 60 casos — iel 10\%! — el lugar indicado en la edición no coincide con el archivo. ${ }^{111}$

\section{TABLA 2}

\section{NORMAS DE TRANSCRIPCIÓN EN LAS EDICIONES DE CARTAS DE EMIGRANTES}

\begin{tabular}{lcccc} 
Edición & $\begin{array}{c}\text { Normas } \\
\text { expuestas }\end{array}$ & Ortografía & Mayúsculas/acentos/ \\
puntuación & $u / v$ \\
\hline Otte, 1988 & No & modern. & modern. & modern. \\
Garmendia, 1989 & No & modern. & modern. & modern. \\
Kessell, 1989 & Sí & original & original & modern. \\
Macías y Morales, 1991 & No & modern. & modern. & modern. \\
Usunáriz, 1992 & Sí & original & modern. & original \\
Dodge y Hendricks, 1993 & Sí & original & original & modern. \\
Márquez, 1994 & No & original & modern. & modern. \\
Jacobs, 1995 & No & original & original & modern. \\
Aramburu, 1999 & Sí & original & modern. & original \\
Pérez, 1999 & No & modern. & modern. & modern. \\
Sánchez y Testón, 1999 & Sí & modern. & modern. & modern. \\
Martínez, 2007 & Sí & original & modern. & original \\
Fernández Alcaide, 2009 & Sí & original & original* & original** \\
Arbelo, 2010 & Sí & original & modern. & modern. \\
Stangl, 2012 & Sí & original & modern. & modern. \\
& & & & \\
\hline \multirow{2}{*}{$*$ Con excepción de mayúsculas. } & & &
\end{tabular}

110 Una tabla con las identificaciones se encuentra en Stangl, 2012, 317.

111 Ibidem, 315. 


\section{TABLA 3}

\section{INTERVENCIONES EDITORIALES EN EDICIONES DE CARTAS DE EMIGRANTES}

\begin{tabular}{|c|c|c|c|c|c|}
\hline Edición & $\begin{array}{l}\text { Método } \\
\text { principal }\end{array}$ & Lagunas & Abreviaturas & Comentarios & $\begin{array}{l}\text { Transcripción de } \\
\text { Lugar/fecha }\end{array}$ \\
\hline Otte, 1988 & ( ) & - & resueltas & -/(sic) & $\begin{array}{l}\text { original y cabeza de } \\
\text { carta (estandarizada }\end{array}$ \\
\hline Garmendia, 1989 & ( ) & - & resueltas & (normal) & inconsecuente \\
\hline Kessell, 1989 & [ ] & - & resueltas (cursiva) & [normal] & $\begin{array}{l}\text { original } \\
\text { y metainformación }\end{array}$ \\
\hline Macías y Morales, 1991 & ( ) & (?)/(roto) & resueltas & (normal) & $\begin{array}{l}\text { original } \\
\text { y metainformación }\end{array}$ \\
\hline Usunáriz, 1992 & [ ] & {$[\ldots]$} & resueltas & 一 & $\begin{array}{l}\text { original } \\
\text { y metainformación }\end{array}$ \\
\hline Dodge y Hendricks, 1993 & [ ] & - & resueltas (cursiva) & [normal] & $\begin{array}{l}\text { original } \\
\text { y metainformación }\end{array}$ \\
\hline Márquez, 1994 & () & (?) & resueltas & - & $\begin{array}{l}\text { pie de carta } \\
\text { y metainformación }\end{array}$ \\
\hline Jacobs, 1995 & [ ] & {$[\ldots ?]$} & resueltas con [ ] & - & $\begin{array}{l}\text { original y cabeza } \\
\text { de carta }\end{array}$ \\
\hline Aramburu, 1999 & ( ) & (?)/(roto) & resueltas & (normal) & $\begin{array}{l}\text { original } \\
\text { y metainformación }\end{array}$ \\
\hline Pérez, 1999 & ( ) & (?) & resueltas & (normal) & $\begin{array}{l}\text { original } \\
\text { y metainformación }\end{array}$ \\
\hline Sánchez y Testón, 1999 & ( ) & $(\ldots)$ & resueltas & en notas & $\begin{array}{l}\text { original } \\
\text { y metainformación }\end{array}$ \\
\hline Martínez, 2007 & ( ) & {$[\ldots]$} & resueltas & (cursiva) & $\begin{array}{l}\text { original } \\
\text { y metainformación }\end{array}$ \\
\hline Fernández Alcaide, 2009 & [ ] & {$[\ldots]$} & $\begin{array}{l}\text { no resueltas } \\
\text { y resueltas con [ ] }\end{array}$ & en notas & original \\
\hline Arbelo, 2010 & [ ] & {$[\ldots]$} & $\begin{array}{l}\text { resueltas, } \\
\text { con excepciones } \\
\text { (fha, dho...) }\end{array}$ & [cursiva] & $\begin{array}{l}\text { sólo en la } \\
\text { metainformación }\end{array}$ \\
\hline Stangl, 2012 & [ ] & {$[\ldots]$} & resueltas con [ ] & $<$ normal $>$ & $\begin{array}{l}\text { original } \\
\text { y metainformación }\end{array}$ \\
\hline
\end{tabular}

\section{Perspectivas para futuras ediciones: el paradigma XML}

Como hemos visto en este repaso por el desarrollo de las ediciones de cartas privadas transatlánticas, el interés en este tipo de fuente no ha cesado, sino que aparentemente incluso sigue creciendo. Ahora, ¿qué se puede 
advertir en cuanto a las normas y el proceder de futuras ediciones? Por supuesto, las normas se deben fundar en las particularidades de las fuentes, pero también hay matices comunes que hay que observar. Espero que las normas delineadas con detalle en mi edición puedan servir como punto de partida para futuros esfuerzos, ${ }^{112}$ tal como a mí las muy detalladas de María del Carmen Martínez me han servido de norte.

Pero tal vez la historiografía hispanoamericanista puede saltar este paso y llegar directamente al hoy, exponiéndose al arte arcana de las ediciones digitales. La comunidad científica se encuentra en un proceso revolucionario en la preparación de fuentes primarias. Cuando en los siglos XIX y XX lo óptimo para la difusión del conocimiento de fuentes primarias sobre la historia hispanoamericana fueron las «colecciones de documentos inéditos» a veces monumentales, hoy la tarea de Hércules para los historiadores consiste en presentar tales fuentes en ediciones digitales. Estas últimas tienen la ventaja de accesibilidad libre y también brillan por poder filtrar resultados, buscar términos y ser flexibles en cuanto a la visualización. Además, obligan al editor a pensar cibernéticamente y crear un modelo esctricto, eliminando así el problema de poca reflexión en el método.

En el ámbito de las humanidades existe un código casi-estándar para ediciones digitales, desarrollado paso a paso a partir de 1987 por el consorcio TEI (Text Encoding Initiative). ${ }^{113}$ En España aún no tiene la misma posición destacada como en el ámbito anglosajón o alemán, pero también en España se va difundiendo cada vez más. ${ }^{114}$ El TEI es una variante del «lenguaje de marcado extensible» XML — un primo del HTML—, usando tags $(<></>)$ para marcar textos de todo tipo, y dispone de herramientas específicas para ediciones de manuscritos, ediciones críticas, poesía, etc. Aún no existe un subset hecho a medida para correspondencias, pero un «grupo de interés especial» está trabajando en ello ${ }^{115}$ y aún así existen varias ediciones de correspondencias elaboradas en TEI. ${ }^{116}$ Cada documento TEI

112 Ibidem, suplemento electrónico, 2-3.

113 http://www.tei-c.org/ [21 de mayo de 2013].

114 En 2011 se fundó la asociación «Humanidades digitales hispánicas» por las profesoras Carmen Isasi (U. de Deusto) y Sagrario López Poza (La Coruña). Los días 2 y 3 de julio de 2012 se realizó un congreso en la Universidad de La Coruña con el lema «Humanidades digitales: edición y difusión».

115 http://www.tei-c.org/Activities/SIG/Correspondence/ [21 de mayo de 2013].

116 «Carl-Maria-von-Weber-Gesamtausgabe»: http://www.weber-gesamtausgabe.de; «DALF Digital Archive of Letters by Flemish Authors and Composers from the 19th \& 20th century»: http://www.kantl.be/ctb/project/dalf/; «Vincent van Gogh — The Letters»: http://vangoghletters.org/ [21 de mayo de 2013]. 
contiene una parte reservada a metainformaciones $(<$ teiHeader $>)$ y otra para el texto mismo $(\langle t e x t\rangle)$ y cuenta con elementos bien definidos para marcar lagunas $<$ gap/ $>$, partes de difícil lectura (<unclear $>$ ), partes rotas $(<$ damage $>)$, abreviaturas $(<$ abbr $>$ ) y su desarrollo (<expan $>0<$ ex $>$ ), adiciones editoriales $(<$ supplied $>)$, cambios de línea o folio $(<\mathrm{lb} />,<\mathrm{pb} />)$, cambio de manos de escribiente (<handShift/>) y muchísimos más elementos y atributos, especificando por ejemplo las causas de partes rotas o la extensión de una laguna, identificando además nombres propios, fechas, lugares, etc. Luego se puede transformar un documento TEI (usando un archivo XSLT) en HTML, PDF, ePub u otro formato, visualizando un mismo código en formas muy diversas.

¿Cuántos lectores habré perdido en la última página, utilizando tantos términos de informática? El mayor problema en lo que se refiere a ediciones digitales es por supuesto la formación de los historiadores, por lo que tales proyectos son muchas veces solo realizables en cooperación con centros de informática y el historiador, como se sabe, sigue siendo en esencia un académico eremita en su torre de marfil individual. Para hacer un primer paso, actualmente estoy preparando una edición digital en TEI de una serie de 92 cartas privadas conservadas en el AHN, escritas en 1822/1823 por (ex-)soldados, comerciantes y algunas también por mujeres desde Puerto Rico y otros puntos del Caribe español, incluso desde el asediado Puerto Cabello. ${ }^{117}$ Para ejemplificar lo arriba esbozado acerca del paradigma XML y la flexibilidad de visualización, se reproduce aquí como apéndice el código de la parte $<$ text $>$ de la carta más corta del conjunto de las cartas, así como dos posibles visualizaciones del mismo código: una más simple que enfatiza la legibilidad y otra semi-paleográfica que conserva más el carácter del documento original.

\section{Conclusiones}

¿Cuáles serán las cartas que se editarán en el futuro (sean digitales o impresas o publicadas en ambas formas) y para las que espero sean útiles las normas exigidas en mi edición de cartas de llamada? Con mi reciente edición, las cartas de llamada son esencialmente explotadas, y solo para las

117 AHN, Estado, 6375, 13-15. Una carta (AHN, Estado, 6375, 15, 21) ya se ha publicado en Earle, 2003, aunque en su edición falta un párrafo. 
posesiones españoles en el Caribe del siglo XIX todavía hay un número relevante de cartas de llamada inéditas en el AGI. ${ }^{118}$

En cuanto a repositorios de otros tipos de cartas transatlánticas aún no explotados hay que esperar que se encontrará material análogo al de Navarra y Álava (Usunáriz y Aramburu) en fondos judiciales y notariales de archivos históricos regionales, provinciales y municipales de otras regiones. Considero estas cartas especialmente interesantes por ser menos estandarizadas que las cartas de llamada y a la vez menos reducidas a las capas altas de la sociedad que las cartas de archivos privados/familiares y archivos de las instancias superiores de justicia, aunque también estoy esperando con ansias la edición de cartas decimonónicas del Archivo de la Real Chancillería de Valladolid de Ana Gimeno Gómez anunciada por Martínez. ${ }^{19}$ También la edición anunciada pero no efectuada de cartas del Tribunal de la Inquisición de Lima podría contribuir significantemente al saber con respecto a las vidas en la América colonial, sobre todo si las cartas con diferencia a El hilo que une se acompañen con resúmenes de los casos asociados y una mención de la relevancia de las cartas para los procesos. Lo que aún falta penosamente para llegar a una visión más completa de las relaciones transatlánticas, es la edición de un número relevante de cartas escritas en la Península y mandadas a América, que deben de existir en archivos americanos.

También 25 años después de la publicación de las Cartas de emigrantes a Indias, el interés en cartas privadas sigue creciendo. Son tesoros tanto para el público interesado que busca informaciones genealógicas de sus antepasados como para investigadores por ser fuentes «blandas» $\mathrm{y}$ «vivas» para el estudio de «mentalidades» o «cambios de actitudes», así como fuentes «duras» para estudiar redes personales, cambios lingüísticos o el sistema de comunicaciones transatlántico y otros muchos temas. Espero que este repaso bibliográfico y metodológico pueda contribuir a amplificar la gama de documentos usados para tales estudios temáticos, a impulsar nuevas ediciones y a reconsiderar las prácticas de ellas.

Recibido el 24 de septiembre de 2012 Aceptado el 2 de abril de 2013

118 Sobre todo en AGI, Ultramar, 326-342. Una tabla con los legajos que contienen tales cartas y qué ediciones se basan en qué legajos se encuentra en Stangl, 2010, 11.

119 Martínez Martínez, 2007, 25, nota 55. 



\section{Apéndice}

\section{Código-TEI de una carta y posibles visualizaciones (usando XSLT)}

\section{I: Código}

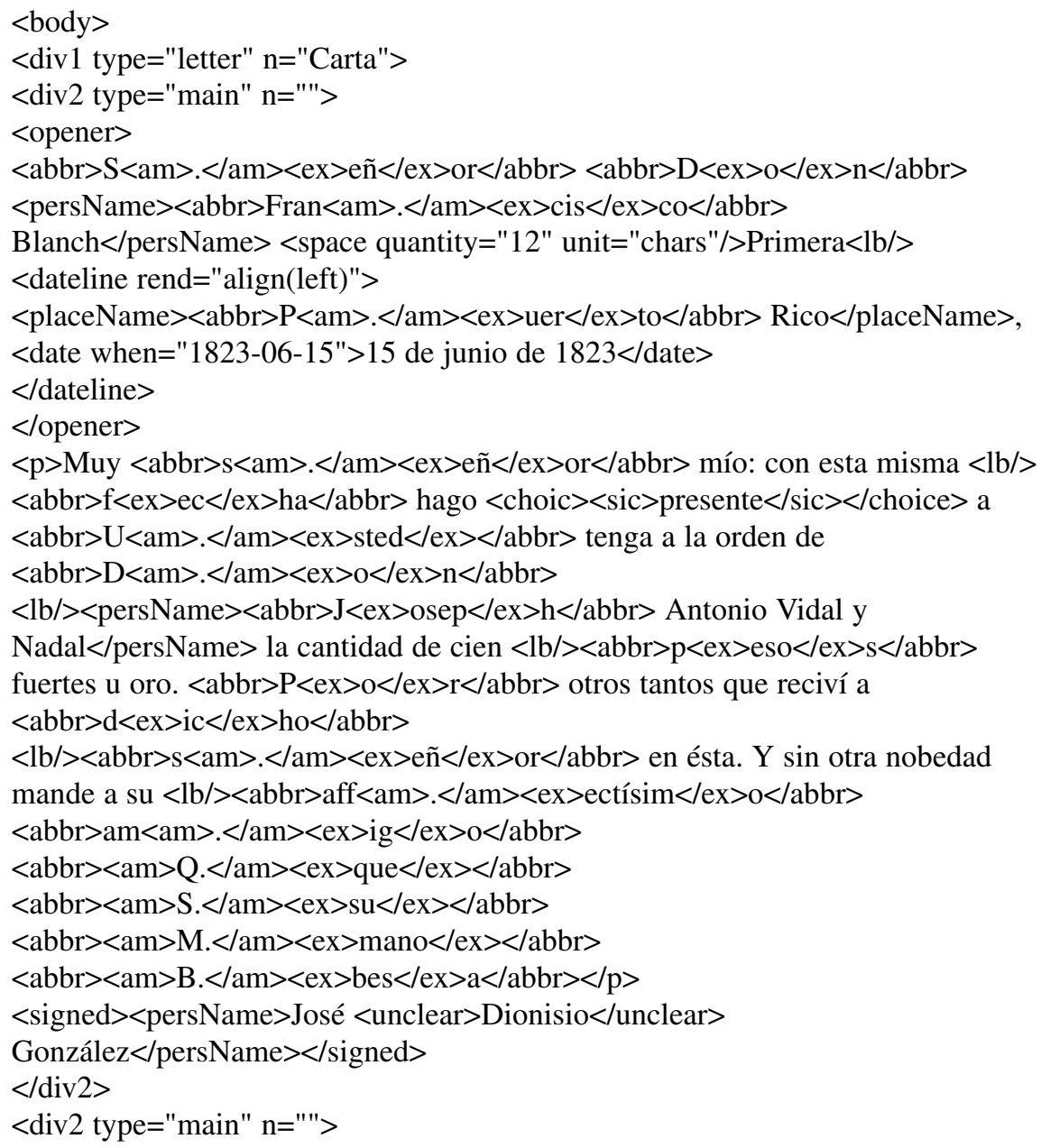


$<$ p $><$ handShift new $=" 2 " /></$ p $>$

$<$ p $>$ Pagare por mí $<$ gap $/>$ a $<$ abbr $>$ D $<$ am $>$. $</$ am $><$ ex $>$ oñ $</$ ex $>$ a $</$ abbr $>$

$<$ persName $>$ Rosa Soler de $<\mathrm{lb} />$ Vidal $<$ /persName $>$ ho vien a mi

$<$ abbr $>$ s $<$ ex $>$ eñ $</$ ex $>$ or $</$ abbr $>$ padre $<$ abbr $>$ D $<$ ex $>$ o $</$ ex $>$ n $</$ abbr $>$

$<$ persName $>$ Antonio $<\mathrm{lb} />$ Vidal $\mathrm{y}<$ add place $=$ "above" $>$

Tort $<$ /add $><$ /persName $>$, vecinos de $<$ placeName $>$ Villanueva $\mathrm{y}$

Geltrú $</$ placeName $>.</$ p $>$

$<$ dateline rend="align(left)" $><$ placeName $>$ Puerto Rico $<$ /placeName $>,<$ date when="1823-06-20" $>20$ de junio $1823</$ date $></$ dateline $>$

$<$ signed $><$ persName $>$ Josef A. Vidal y Nadal $<$ /persName $><$ /signed $>$

$</ \operatorname{div} 2>$

$</$ div $1>$

$<$ /body $>$

\section{II: Visualización (a)}

Señor Don Francisco Blanch Primera Puerto Rico, 15 de junio de 1823

Muy señor mío: con esta misma fecha hago presente a Usted tenga a la orden de Don Joseph [?] Antonio Vidal y Nadal la cantidad de cien pesos fuertes u oro. Por otros tantos que reciví a dicho señor en ésta. Y sin otra nobedad mande a su affectísimo amigo que su mano besa

José Dionisio González

Pagare por mí a Doña Rosa Soler de Vidal ho vien a mi señor padre Don Antonio Vidal y Tort, vecinos de Villanueva y Geltrú.

Puerto Rico, 20 de junio 1823

Josef A. Vidal y Nadal

\section{Visualización (b)}

S.or D.n Fran.co Blanch Primera P.to Rico, 15 de junio de 1823 Muy s.or mío: con esta misma fha hago presentre a $\mathrm{U}$. tenga a la orden de D.n Jh [?] Antonio Vidal y

Nadal la cantidad de cien p.s fuertes u oro. P.r otros tantos que reciví a dho s.or en ésta. Y sin otra nobedad mande a su aff.mo am.o Q.S.M.B. José Dionisio González

[Nueva mano:]

Pagare por mí a D.a Rosa Soler de Vidal ho vien a mi señor padre D.n Antonio Vidal y ${ }^{\text {Tort }}$, vecinos de Villanueva y Geltrú.

Puerto Rico, 20 de junio 1823

Josef A. Vidal y Nadal 


\section{Bibliografía}

Alfaro Ramírez, Gustavo Rafael: «¿Quién encarceló al alguacil mayor de Puebla? La vida, los negocios y el poder de don Pedro de Mendoza y Escalante, 16951740», Estudios de historia novohispana, 17, México, 1997, 31-62.

Altuna, Elena: «Imágenes del Perú y protocriollismo en las cartas privadas de los inmigrantes», Revista de Crítica Literaria Latinoamericana, XXVI, Medford, Mass., 52, 2000, 215-225.

Alvar, Manuel: «La investigación del español en América. Proyectos inmediatos», en Blecua, José Manuel (ed.), Actas del Congreso de la Lengua Española, Sevilla del 7 al 10 Octubre, 1992, Madrid, Instituto Cervantes, 1994, 53-78.

Andonegi, Romero: «La edición filológica de documentos desde una perspectiva diplomática», Oihenart, 21, Bilbao, 2006, 425-439.

Angulo Morales, Alberto: «"El más feliz exitto de su desttino...”. Medios de integración del emigrante vasco en América y Europa durante el siglo XVIII», en Álvarez Gila, Oscar y Angulo Morales, Alberto (eds.), Las migraciones vascas en perspectiva histórica (siglos XVI-XX), Bilbao, Universidad del País Vasco, 2002.

Aramburu Zudaire, José Miguel: Vida y fortuna del emigrante navarro a Indias, siglos XVI-XVII, Pamplona, Gobierno de Navarra, 1999.

Arbelo García, Adolfo I.: Al recibo de esta... Relaciones epistolares canario-americanas del siglo XVIII, Santa Cruz de Tenerife / Las Palmas, Ediciones Idea, 2010.

Arrieta González, Ángel M.: La emigración alavesa a América en el siglo XIX, Vitoria, Gobierno Vasco, 1992.

Arroyo, Lara: «Redes de influencia: relaciones privilegiadas en el comercio colonial a finales del siglo XVIII. Los Marticorena y su correspondencia epistolar», Nuevo Mundo / Mundos Nuevos, 7, Paris, 2007, online: http://nuevomundo.revues.org/3213 [21 de mayo de 2013].

Cala Carvajal, Rafael: Edición de epistolarios catalano-cubanos del siglo XIX, tesis inédita, Barcelona, 1999.

Cala Carvajal, Rafael: «El contacto de lenguas castellano-catalán a la luz de los epistolarios catalano-cubanos», Pragmalingüística, 8-9, Cádiz, 2000/2001, 43-60.

Cala Carvajal, Rafael: «La voz de los catalanes emigrados a Cuba, s. XIX. Testimonios epistolares», Boletín Americanista, 53, 2003, 19-33.

Carande, Ramón: «Cartas de mercaderes», Moneda y crédito, 9, Madrid, 1944, 13-50.

Castillo Gómez, Antonio: Escrituras y Escribientes. Prácticas de la Cultura Escrita en una Ciudad del Renacimiento, Las Palmas, Fundación de Enseñanza Superior a Distancia, 1997. 
Company Company, Concepción: Documentos lingüísticos de la Nueva España, altiplano central, México, UNAM, 1994.

Cortés Alonso, Vicenta: «La producción documental en España y América en el siglo XVI», Anuario de Estudios Americanos, 41, Sevilla, 1984, 195-251.

Cortijo Ocaña, Antonio y Cortijo Ocaña, Adelaida: Cartas desde México y Guatemala, 1540-1635. El proceso Díaz de la Reguera, Cáceres, Universidad de Extremadura, 2003.

Craddock, Jerry R.: «Drawing Aside the Veil: A Proposal for 21st Century Editions of the Documents of the Hispanic Southwest», paper read at the Annual Conference and Meeting of the Historical Society of New Mexico. Gallup, New Mexico, April 4-7, 2003, publicado online con enlace permanente: http://escholarship.org/uc/item/8n27h96r [21 de mayo de 2013].

Dodge, Meredith D. y Hendricks, Rick (eds.): Two Hearts, One Soul. The Correspondence of the Condesa de Galve, 1688-96, Albuquerque, University of New Mexico, 1993.

Domínguez Ortiz, Antonio: «Cartas privadas de emigrantes a Indias», Cuadernos hispanoamericanos, 476, Madrid, 1990, 136-137.

Earle, Rebecca: «Briefe und die Liebe im kolonialen Spanisch-Amerika (16. bis 18. Jahrhundert)», en Hämmerle, Christa \& Saurer, Edith (eds.), Briefkulturen und ihr Geschlecht. Zur Geschichte der privaten Korrespondenz vom 16. Jahrhundert bis heute, Colonia/Weimar/Viena, Böhlau, 2003, 135-162.

Fernández Alcaide, Marta: Cartas de particulares en Indias del siglo XVI. Edición y estudio discursivo, Frankfurt, Vervuert, 2009 (con CD-ROM).

García Abásolo, Antonio: «Mujeres andaluzas en la América colonial, 15501650», Revista de Indias, XLIX, 185, Madrid, 1989, 91-110.

García Abásolo, Antonio: La vida y muerte en Indias. Cordobeses en América, siglos XVI-XVIII, Córdoba, Monte de Piedad, 1992.

Garmendia Arruebarrena, José: «Cartas de Ma Eusebia de Eliza a Veracruz», Boletín de la Real Sociedad Bascongada de Amigos del País, XLV, 1-2, 1989, 119-145.

Gimeno Gómez, Ana: «Una visión del Perú de principios del siglo XIX por un comerciante de Lima», en Gutiérrez Escudero, Antonio y Laviana Cuetos, María Luisa (eds.): Estudios sobre América, siglos XVI-XX. La Asociación Española de Americanistas en su vigésimo aniversario, Sevilla, AEA, 2005.

González de Chávez, Jesús: «Notas para la historia de la emigración canaria a América - Cartas de emigrantes canarios, siglo XVIII», en Morales Padrón, Francisco (coord.): V Coloquio de historia canario-americana, Las Palmas, Cabildo Insular, 1982, 111-140.

González Echegaray, María del Carmen: «Pasajeros a Indias del Valle de Toranzo», en Camus, Matilde (ed.), Santander y el Nuevo Mundo, Santander, Centro de Estudios Montañeses, 1979, 177-216. 
Guibovich, Pedro M.: «La usurpación de la memoria: el patrimonio documental y bibliográfico durante la ocupación chilena de Lima, 1881-1883», Jahrbuch für Geschichte Lateinamerikas 46, Colonia, 2009, 83-107.

Hausberger, Bernd: «La red social del alavés Tomás Ruiz de Apodaca», en La Casa de la Contratación y la navegación entre España y las Indias, Sevilla, Universidad de Sevilla / CSIC, 2004, 885-908.

Helmer, Marie: «Un tipo social: el "minero" de Potosí», Revista de Indias, XVI, Madrid, 1956, 85-92.

Helmer, Marie: «Lettres d'Amérique dans la correspondance de Simón Ruiz», en Homenaje a Jaime Vicens Vives, Barcelona, Universidad, 1967, vol. 2, 231-245.

Hernández González, Manuel: «Los mercaderes de origen extranjero en el tráfico canario-americano (1765-1808)», en Crespo Solana, Ana (ed.): Comunidades transnacionales: colonias de mercaderes extranjeros en el mundo atlántico, 1500-1830, Madrid, Doce Calles, 2010, 155-187.

Hidalgo Nuchera, Patricio: Entre Castro del Río y México. Correspondencia privada de Diego de la Cueva y su hermano Juan, emigrante en Indias, 16011641, Córdoba, Universidad de Córdoba, 2006.

Imízcoz Beunza, José María: «El patrocinio familiar. Parentela, educación y promoción de las elites vasconavarras en la monarquía borbónica», en Chacón, Francisco y Hernández, Juan (eds.), Familias, poderosos y oligarquías, Murcia, Universidad de Murcia, 2001, 93-130.

Jacobs, Auke Pieter: Los movimientos migratorios entre Castilla e Hispanoamérica durante el Reinado de Felipe III, 1598-1621, Amsterdam, Rodopi, 1995.

Jiménez de la Espada, Marcos: «Tres cartas familiares de Fr. Juan de Zumárraga, primer Obispo y Arzobispo de México, y contestación a otra que le dirige Fr. Marcos de Niza», Boletín de la Real Academia de la Historia, 6, Madrid, 1885, 239-252, online: http://www.cervantesvirtual.com/ [21 de mayo de 2013].

Kessell, John L.: Remote beyond compare. Letters from Don Diego de Vargas to his family from New Spain and New Mexico, 1675-1706, Albuquerque, University of New Mexico, 1989.

Lamikiz, Xabier: «Patrones de comercio y flujo de información comercial entre España y América durante el siglo XVIII», Revista de Historia Económica / Journal of Iberian and Latin American Economic History, 25, 2, Madrid, 2007, 231-258.

Lamikiz, Xabier: Trade and Trust in the Eighteenth-Century Atlantic World: Spanish Merchants and their Overseas Networks, Woodbridge, Boydell and Brewer, 2010.

Las Casas, Bartolomé de: Brevissima relación de la destruyción de las Indias, s.l., 1552. 
Lockhart, James y Otte, Enrique (eds.): Letters and People of the Spanish Indies, Cambridge, Cambridge University, 1976.

Lohmann Villena, Guillermo: «Cartas de mercaderes. Secretos y confidencias en el comercio privado», en La Casa de la Contratación y la navegación entre España y las Indias, Sevilla, Universidad de Sevilla / CSIC, 2004, 815-841.

López Estrada, Francisco: «Cartas de Indias, escritas en el siglo XVII», Iberida. Revista de Filología, III, 6, Rio de Janeiro, 1961, 115-125.

Macías, Isabelo y Morales Padrón, Francisco: Cartas desde América, 1700-1800, Sevilla, Junta de Andalucía, 1991.

Márquez Macías, Rosario: «La emigración a Indias a través de la correspondencia privada de los emigrantes, 1765-1824», Rábida, 4, Huelva, 1988, 45-54.

Márquez Macías, Rosario: Historias de América: La emigración española en tinta y papel, Huelva, Ertoil Lubricantes, 1994.

Márquez Macías, Rosario: La emigración española a América, 1765-1824, Oviedo, Universidad de Oviedo, 1995.

Márquez Macías, Rosario: «Puerto Rico en el siglo XIX a través de las relaciones epistolares», Rábida, 20, Huelva, 2001, 117-145.

Martínez, José Luis: «Enrique Otte, Descubridor», Ibero-Amerikanisches Achiv, NF 20, 3-4, Berlín, 1994, 437-444.

Martínez Martínez, María del Carmen (ed.): Hernán Cortés. Cartas y memoriales, Valladolid, Universidad de Valladolid, 2003.

Martínez Martínez, María del Carmen (ed.): En el nombre del hijo. Cartas de Martín Cortés y Catalina Pizarro, León, Junta de Castilla y León, 2006

Martínez Martínez, María del Carmen (ed.): Desde la otra orilla. Cartas de Indias en el Archivo de la Real Chancillería de Valladolid, siglos XVI-XVIII, León, Junta de Castilla y León, 2007.

Medina, José Toribio de: Colección de documentos inéditos para la Historia de Chile, desde el viaje de Magallanes hasta la Batalla de Maipo, 1518-1818, tomo 9: Valdivia y sus compañeros, Santiago de Chile, Ercilla, 1898.

Ministerio de Fomento (ed.): Cartas de Indias, Madrid, Hernández, 1877.

Morales, Adolfo de: «Cartas privadas escritas desde América en el siglo XVI», Revista de Cultura. Cochabamba, 4, 4, Cochabamba, 1964, 200-212.

Moutoukias, Zacarías: «Réseaux de négociants ou réseaux ego centrés. Une approche méthodologique», en Beaurepaire, Pierre-Yves \& Taurisson, Dominique (eds.), Les Ego-documents à l'heure de l'électronique. Nouvelles approches des espaces et des réseaux relationnels, Montpellier, Université Paul ValéryMontpellier III, 2003.

Otte, Enrique: «Nueve cartas de Diego de Ordás», Historia Mexicana, XIV, 1, México, 1964, 102-130 y XIV, 2, México, 1964, 321-338.

Otte, Enrique: «Mercaderes vascos en Tierra Firme a raíz del descubrimiento del Perú», Mercurio Peruano, 443/444, Lima, 1964, 81-89. 


\section{UN CUARTO DE SIGLO CON CARTAS PRIVADAS DE EMIGRANTES A INDIAS}

Otte, Enrique: «Cartas privadas de Puebla del Siglo XVI», JbLA, 3, Colonia, 1966, 10-87.

Otte, Enrique: «Semblanza espiritual del poblador de Indias, siglos XVI-XVII», Verhandlungen des XXXVIII. Internationalen Amerikanistenkongresses, Múnich, Renner, 1968, vol. III, 441-449.

Otte, Enrique: «Mercaderes Burgaleses en los inicios del comercio con México», Historia Mexicana XVIII, 1, México, 1968, 108-144 y XVIII, 2, México, 1968, 258-285.

Otte, Enrique: «Die europäischen Siedler und die Probleme der Neuen Welt», JbLA, 6, Colonia, 1969, 1-40.

Otte, Enrique: «La Nueva España en 1529», en García Martínez, Bernardo (coord.), Historia y Sociedad en el mundo de habla española. Homenaje a José Miranda, México, El Colegio de México, 1970, 95-111.

Otte, Enrique: «Juan de Zumárraga, poblador», Anuario de Historia X, México, 1978-1979, 87-94.

Pareja Ortiz, María del Carmen: «Las cartas de familia y la vida cotidiana de la mujer en Indias», en Andalucía y América. Actas del II Congreso de Historia de Andalucía, Córdoba 1991, Córdoba, Consejería de Cultura y Medio Ambiente, 1994, 105-116.

Pascua Sánchez, María José de la: Mujeres solas. Historias de amor y de abandono en el mundo hispánico, Málaga, Diputación de Málaga, 1998.

Paso y Troncoso, Francisco del: Epistolario de la Nueva España, México, Porrúa, 1939-1942, 16 vols.

Pérez Murillo, María Dolores: «Testimonios de emigrantes vascos en Cuba en las primeras décadas del siglo XIX», en Escobedo, Ronald y Zaballa Beascoechea, Ana de (coords.), Emigración y redes sociales de los vascos en América, Vitoria, Universidad del País Vasco, 1996, 91-103.

Pérez Murillo, María Dolores: Cartas de emigrantes escritas desde Cuba. Estudio de las mentalidades y valores en el siglo XIX, Sevilla, Aconcagua / Cádiz, Universidad de Cádiz, 1999.

Pescador, Juan Javier: «"Thío Señor y Muy dueño mío”. Cartas de Indias de la familia Urdinola del Valle de Oyarzún, 1700-1708», Boletín de la Real Sociedad Bascongada de Amigos del País, 52, 2, Donostia-San Sebastián, 1996, 503-518.

Plummer, Ken: Documents of Life. An Introduction to the Problems and Literature of a Humanistic Method, Londres, Allen and Unwin, 1983.

Porras Barrenechea, Raúl: Cartas del Perú, 1524-1543, Lima, Sociedad de Bibliófilos Peruanos, 1959.

Rodríguez Mendoza, Félix: La emigración del noroeste de Tenerife a América durante 1750-1830, La Laguna, Universidad de La Laguna, 2004, CD-ROM.

Rodríguez Morel, Genaro: «Cartas privadas de Hernando Gorjón», Anuario de Estudios Americanos, LII, 2, Sevilla, 1995, 203-233. 
Rubio y Moreno, Luis: Pasajeros a Indias. Catálogo Metodológico de las Informaciones y Licencias de los que allí pasaron, existentes en el Archivo General de Indias. Siglo primero de la colonización de América, 1492-1592, Madrid, Comp. Ibero-Americana de Publicaciones, 1930, vol. 1.

Ruiz Fernández, Francisco: Fonética del español de América del siglo XVI en cartas de emigrados andaluces a Indias, Cádiz, Universidad de Cádiz, 1993, CD-ROM.

Sánchez, Rubio Rocío y Testón Núñez, Isabel: El hilo que une. Las relaciones epistolares en el Viejo y el Nuevo Mundo, siglos XVI-XVIII, Mérida, Universidad de Extremadura, 1999.

Solano, Francisco de: «Elites y calidad de vida en Chucuito a mediados del siglo XVII, según la correspondencia privada de un noble gaditano», Histórica, XVI, 2, Lima, 1992, 221-270.

Stangl, Werner: «Communicative behaviour in private transatlantic correspondences of 18th-century Spanish emigrants - continuities and changes», en Delia, Luigi y Zygel-Basso, Aurélie (comps.), L'Europe et le monde colonial au XVIIIème siècle, París, Champion, 2013, 39-61.

Stangl, Werner: Zwischen Authentizität und Fiktion. Die Korrespondenz spanischer Emigranten aus Amerika, 1492-1824, Colonia / Weimar / Viena, Böhlau, 2012. La publicación dispone de suplemento electrónico accesible vía www.boehlau.de [21 de mayo de 2013].

Stangl, Werner: «Consideraciones metodológicas acerca de las cartas privadas de emigrantes españoles desde América, 1492-1824. El caso de las "cartas de llamada"», JbLA, 47, Colonia, 2010, 11-35.

Testón Nuñez, Isabel y Sánchez, Rubio Rocío: «"Aunque no hacía nada por mí, su sombra llegaba hasta acá". Solidaridades y redes relacionales en la familia castellana del siglo XVI. Los Espadero-Paredes de Extremadura», en Barbazza, Marie Catherine/Heusch, Carlos (eds.), Familles, Pouvoirs, Solidarités. Domaine méditerranéen et hispano-americain XVe-XXe siècle, Montpellier, Université de Montpellier III, 2002, 35-64.

Usunáriz Garayoa, Jesús María: Una visión de América del XVIII. Correspondencia de emigrantes guipuzcoanos y navarros, Madrid, MAPFRE, 1992.

Vollmer, Günter: «In memoriam: Enrique Otte, 1923-2006», JbLA 43, Colonia, 2006, XIII-XVI. 